\title{
Gaze Control During Interceptive Actions With Different Spatiotemporal Demands
}

\author{
José A. Navia \\ Technical University of Madrid
}

John van der Kamp

Vrije Universiteit Amsterdam and University of Hong Kong

\author{
Matt Dicks \\ University of Portsmouth
}

Luis M. Ruiz

Technical University of Madrid

\begin{abstract}
It is widely accepted that the sources of information used to guide interceptive actions depend on conflicting spatiotemporal task demands. However, there is a paucity of evidence that shows how information pick-up during interceptive actions is adapted to such conflicting constraints. The present study therefore examined the effects of systematic manipulations of spatiotemporal constraints on performance, timing and gaze in an in situ interceptive action. To this end, expert futsal goalkeepers faced penalty kicks taken from $10 \mathrm{~m}$ and $6 \mathrm{~m}$. With the more lenient spatiotemporal constraints (i.e., kicks from $10 \mathrm{~m}$ ), the goalkeepers saved more kicks, initiated their actions later, and looked longer toward ball relative to the penalty takers' body. Furthermore, analysis of gaze patterns showed that interindividual variations in information pick-up were related to the unfolding of the penalty taker's action, revealing a less variable, funnel-like gaze pattern toward the end of the action. These findings are interpreted to reflect that changes in spatiotemporal demands induce the differential use of information for the accurate control of interceptive actions.
\end{abstract}

\section{Public Significance Statement}

When facing penalty kicks, expert goalkeepers can ensure that they dive to the correct goal location if they wait until ball flight. However, in doing so, goalkeepers are likely to move too late for ball interception. Alternatively, goalkeepers can move early and anticipate based on the actions of the penalty taker. We examined how elite futsal goalkeepers adapt to these conflicting spatiotemporal demands by examining their attempts to save penalty kicks taken from $10 \mathrm{~m}$ and $6 \mathrm{~m}$. Goalkeepers prioritized moving early to arrive in sufficient time to intercept the ball, although such action coincided with a decrease in anticipation accuracy during 6-m compared to 10-m kicks. These findings are important for the study of perception and action during social coordination (as exemplified by 2 opponents in sport situations) as the use of video or virtual reality (VR)technologies in research fail to safeguard the temporal nature of real-time interactions.

Keywords: information pick-up, gaze patterns, interceptive action, constraints, expertise

Skilful behavior across a multitude of daily events is evidenced by the ability of humans to accurately control their actions relative to complex environmental demands. As such, in the experimental psychology literature, there has been a long-established focus on exam-

José A. Navia, Faculty of Physical Activity and Sport Sciences, Technical University of Madrid; Matt Dicks, Department of Sport and Exercise Science, University of Portsmouth; John van der Kamp, MOVE Research Institute, Faculty of Behavioural and Movement Sciences, Vrije Universiteit Amsterdam, and Institute of Human Performance, University of Hong Kong; Luis M. Ruiz, Faculty of Physical Activity and Sport Sciences, Technical University of Madrid.

This research was supported by a grant from the Spanish Ministry of Education (AP2008-01315) awarded to José A. Navia.

Correspondence concerning this article should be addressed to José A. Navia, Faculty of Physical Activity and Sport Sciences, Technical University of Madrid, 28040 Madrid, Spain. E-mail: joseantonio.navia@upm.es ining the processes underpinning the control of perception and action within natural contexts that have conflicting spatiotemporal demands (Fajen, 2005; Faisal \& Wolpert, 2009). Historically, understanding on the limits of skillful human behaviors have broadly been enriched by both observations (e.g., Bartlett, 1932) and, more recently, through the systematic study of expert sport performers (e.g., Land \& McLeod, 2000; Yarrow, Brown, \& Krakauer, 2009). Indeed, there has been a call for renewed emphasis on the importance of studying elite sport performers to develop current understanding about the complex processes underlying human behavior (Walsh, 2014). With this in mind, the current study aims to systematically measure gaze and movement behaviors of elite athletes (futsal goalkeepers) to further understand how perception and action are adapted to naturally occurring changes in complex and contradictory spatiotemporal demands.

Research indicates that the sources of information exploited during interceptive actions vary relative to the constraints arising from the interrelation between an athlete's action capabilities and 
the spatiotemporal demands of the situation (e.g., Dicks, Davids, \& Button, 2010c; Triolet, Benguigui, Le Runigo, \& Williams, 2013). For example, Triolet et al. (2013) reported that the accuracy of world-class tennis players' performance was dependent on spatiotemporal demands. Players consistently moved to the correct interception point during less-demanding situations (e.g., baseline rallies). In contrast, under high-demanding instances (e.g., passing shots), players moved early but to the incorrect interception point, including the wrong side of the court. These observations suggest that more lenient spatiotemporal constraints allowed players to wait longer and move after the opponent contacted the ball and therefore exploit reliable ball flight information. In contrast, under more pressured time constraints, players had to move well before the opponent contacted the ball, meaning that actions were guided by less reliable information from the opponent's body movements (e.g., Huys, Smeeton, Hodges, Beek, \& Williams, 2008) or from the situation at large (often denoted as situational probabilities or situational information; cf. Abernethy, Gill, Parks, \& Packer, 2001; cf. Navia, van der Kamp, \& Ruiz, 2013).

There is a paucity of research that has systematically manipulated the time and space demands of naturally occurring sport situations to assess how this affects the perception and action processes of elite athletes (but see Brenner, Driesen, \& Smeets, 2014; Faisal \& Wolpert, 2009). Concomitantly, there is a lack of research that has examined whether and how information pick-up and gaze control are adapted to different spatiotemporal demands. Panchuk and Vickers (2006) examined the behaviors of ice hockey goaltenders when they attempted to save shots from 5 and $10 \mathrm{~m}$. Despite changes in time constraints between the two conditions, the goaltenders' performances and gaze behaviors did not vary as a function of distance. Given the small dimensions of the space (goal) defended by elite ice hockey goaltenders, it is plausible that there is less demand to anticipate the direction of the puck. Hence, the current study sets out to further explore how elite athletes adapt information pick-up and gaze control to different spatiotemporal demands. Specifically, this study examines how expert (professional) goalkeepers attempt to block futsal (i.e., indoor soccer) penalty kicks taken from different distances.

During interception tasks, human behavior is primarily constrained by time (i.e., onset of one's own action and movement duration) and space (i.e., distance to the interception point; Battaglia \& Schrater, 2007). During interpersonal interactions in fastball sport situations, specifically, the speed and trajectory of the target object are determined by the opponent's actions and the subsequent field dimensions that the athlete must cover to intercept the object (e.g., see Vilar, Araújo, Davids, Correia, \& Esteves, 2013). For example, in the case of the soccer penalty, to stop a kick directed to one of the corners of the goal from a distance of $11 \mathrm{~m}$, goalkeepers are required to move laterally (from the center of the goal, $7.32 \mathrm{~m}$ wide), covering a distance of approximately $3.66 \mathrm{~m}$. This lateral movement (dive) can take between 700 and 1,100 ms (Dicks et al., 2010c). Following the penalty taker's foot-ball contact, the ball can reach the goal between 350 and $600 \mathrm{~ms}$ (Dicks et al., 2010c; Morya, Bigatăo, Lees, \& Ranvaud, 2005; Nuñez, Oña, Bilbao, \& Raya, 2005). Waiting to initiate the action until the ball is in flight typically leaves the goalkeeper with insufficient time to intercept. Thus, it is necessary for a goalkeeper to adapt the timing of actions to ensure that time-to-interception does not exceed her or his maximal action capabilities (see Fajen, 2007).
Such regulation of interceptive actions resonates with Fajen's (2005) model of affordance-based control, whereby he proposed that a performer's own capabilities place an action boundary on the control of subsequent actions.

The situation described above places the goalkeeper at a disadvantage relative to the penalty taker. In essence, the difficulty for the goalkeeper is one of weighing space against time. Confronted with these conflicting spatiotemporal demands, a goalkeeper can wait until the ball is kicked-and thus increase the likelihood of diving to the correct side- however, such action is typically too late for ball interception. Conversely, the goalkeeper can dive early, before the ball is kicked. Yet, prioritizing time can lead to inaccurate anticipation of which side of the goal the ball will travel toward. To adapt to conflicting spatiotemporal demands, literature has therefore focused on examining whether expert athletes are able to anticipate the actions of others via attunement to biological motion information (Diaz, Fajen, \& Phillips, 2012; Yarrow et al., 2009).

Due to biomechanical constraints, research shows that the closer the penalty taker is to ball-contact, the smaller the variance in the kinematics of the kicking action (Diaz et al., 2012; Lopes, Jacobs, Travieso, \& Araújo, 2014). This means that the information for anticipation of kick direction from the penalty taker's action increases in reliability over the duration of the run-up and the kick. For instance, the angle of approach is less reliable (i.e., there is only a correlation of 0.5 with ball direction) than the final orientation of the nonkicking foot at the end of the approach (i.e., a correlation of 0.85 ; Lees \& Owens, 2011). Indeed, analyses indicate that kinematics do not become fully predictive of shot direction until the ball is kicked (Diaz et al., 2012; Lopes et al., 2014). In other words, the earlier the goalkeeper dives to ensure reaching the ball in time, the less reliable the available information is, with respect to ball direction. This is exacerbated when penalty takers use deception (e.g., Smeeton \& Williams, 2012), because penalty takers are more capable of varying their movements in the early parts of the run-up compared to closer to foot-ball contact (Lopes et al., 2014). For instance, Dicks, Button, and Davids (2010a, p. 1119 , Figure 2) reported that the effect of deception was greatergoalkeeper performance decreased-when goalkeepers anticipate penalty kick direction on the basis of earlier run-up information (e.g., angle of approach). In contrast, the effect of deception decreased and anticipation accuracy increased when goalkeepers appeared to base their actions on the kinematic information that unfolded in the final $250 \mathrm{~ms}$ before foot-ball contact.

Researchers have assessed gaze patterns as a means to gain understanding on information pick-up during interceptive actions (e.g., Mann, Williams, Ward, \& Janelle, 2007). For example, Savelsbergh and colleagues reported that expert goalkeepers fixated toward the nonkicking leg of the penalty takers while responding to recorded video clips by simulating their dive by means of joystick movements (Savelsbergh, van der Kamp, Williams, \& Ward, 2005; Savelsbergh, Williams, van der Kamp, \& Ward, 2002). However, a concern highlighted across different domains of biological motion perception (e.g., Lappi, 2016) and social attention research (e.g., Schilbach et al., 2013) is that video-based experimental designs do not allow researchers to truly capture, interactive real-time encounters. That is, many studies have implicitly assumed that information pick-up and gaze control are independent of the actions produced. As a consequence, there is a 
real need to examine the processes that underpin real-time interpersonal interactions as per natural sport situations (van der Kamp \& Renshaw, 2015; van der Kamp, Rivas, van Doorn, \& Savelsbergh, 2008).

In an in situ study of soccer goalkeeping, Dicks, Button, and Davids (2010b) found that experienced goalkeepers, who were actually trying to intercept a penalty kick, fixated the opponent's body in the early parts of the run-up before shifting toward the ball in the latter part of the approach. In fact, the ratio of the time spent attending to the body relative to the ball was 0.49 (see Dicks et al., 2010b, p. 715, Figure 6, in situ interception [ISI] condition). The goalkeepers looked as much to the body as they did to the ball. In a similar study, Piras and Vickers (2011) compared goalkeepers' gaze patterns when facing penalty kicks executed with either the inside (lower ball velocity) or instep (higher ball velocity) of the foot. The ratios of viewing time toward the body and ball were 0.49 and 0.54 , respectively (see Piras \& Vickers, 2011, p. 250, Table 2). Goalkeepers appeared to look longer at the body relative to the ball under the more demanding spatiotemporal constraints (i.e., shorter ball fight times) of the instep drive. It is noticeable that the ball flight times for kicks with the inside of the foot (but not the instep) were similar to the flight times reported in the Dicks et al. (2010b) study and resulted in the same body/ball gaze ratio. Most importantly, these findings suggest that gaze (and presumably information use) may be tightly adapted to the task's spatiotemporal demands.

In sum, the pick-up of information in the guidance of interceptive actions in fastball sports appears to be contingent upon the spatiotemporal demands of the situation (e.g., Dicks et al., 2010c; Triolet et al., 2013). Further to existing interceptive action research, in the current study, we systematically manipulated time constraints and captured gaze control in one single experiment. We directly manipulated the spatiotemporal demands in a penalty kick situation by comparing goalkeeper performance in response to deception and nondeception futsal penalties executed from 6 and $10 \mathrm{~m}$. We hypothesized that, in comparison with kicks from $6 \mathrm{~m}$, when confronted with the less temporally demanding penalty kicks from $10 \mathrm{~m}$, goalkeepers would (a) spend more time attending to the ball relative to the body (cf. Panchuk \& Vickers, 2006), (b) wait longer before initiating their movement to intercept the ball (Triolet al., 2013), (c) move more often to the side the ball is kicked (Dicks et al., 2010c), and (d) be less susceptible to deceptive movements of the penalty taker (Dicks et al., 2010a).

\section{Method}

\section{Participants}

Twelve expert futsal goalkeepers (age: $M=23.4$ years, $S D=$ 5.1) volunteered to participate. Participants were professional goalkeepers (playing experience: $M=16.1$ years, $S D=4.8$ ), playing in either the First, Second or Second B division of the Spanish National Futsal League (professional experience: $M=6.1$ years, $S D=5.1)$. In addition, nine professional players, who were matched to the goalkeepers in age $(M=24.2$ years, $S D=)$, playing $(M=15.6$ years, $S D=3.7)$ and professional experience $(M=4.9$, years $S D=3.3)$, were recruited to execute the penalty kicks. Before testing, all players provided written consent, and ethical approval was obtained from the local University's ethics committee.

\section{Apparatus}

All penalty kicks were executed in an indoor sports hall. Field lines, goal $(3 \times 2 \mathrm{~m}$; note that this is approximately half the size of an 11 vs. 11 soccer goal), and ball were in accordance with Fédération Internationale de Football Association laws (International Football Association Board [IFAB], 2016). The actions of the goalkeepers were recorded using a high-speed camera (Casio Exilim FH100, Tokyo, Japan, $120 \mathrm{fps}$ ), which was placed $1 \mathrm{~m}$ behind and $0.5 \mathrm{~m}$ off-center of the ball. This camera location also captured the point of penalty taker foot-ball contact. A second camera (Casio Exilim F1, Tokyo, Japan, $30 \mathrm{fps}$ ) was placed $3 \mathrm{~m}$ to the side of the goalmouth to record the penalty takers' actions (e.g., deception strategy, see below).

The goalkeepers' gaze patterns were recorded using a Mobile Eye tracking system (ASL Mobile Eye, Bedford, MA). This monocular head-mounted eye tracker monitors the location within the visual field at which the participant is looking (i.e., point of gaze) with an accuracy of $\pm 1^{\circ}$ and a precision of $\pm 0.5^{\circ}$, via two cameras mounted on the glasses that record the eye and the scene simultaneously. For each participant, the Mobile Eye was calibrated relative to 18 locations placed to different distances (5 points on a video screen at $0.5 \mathrm{~m}, 9$ points on a grid at $1.5 \mathrm{~m}$, and four field locations at $10 \mathrm{~m}$ ) to avoid parallax effect impeding the calibration accuracy. Following calibration, point of gaze was recorded using a mobile video recorder unit (DVCR, Sony GVD1000E, Oradel, New Jersey), which was worn around the goalkeeper's waist in a modified padded tight-fitting bag. The system was checked regularly after every four kicks and when necessary recalibrated during testing. Furthermore, participants were asked to look toward specific task-related locations at the beginning of each trial to check calibration accuracy, and to allow an eventual offline recalibration of the recordings if any drift had occurred during the trials between calibration verifications (see Dicks et al., 2010b). As in previous research, participants wore a clear shock resistant facemask with a wide aperture in the field of vision to protect the Mobile Eye from the ball (Navia et al., 2013). Although there is potential risk that wearing the Mobile Eye and facemask could negatively impact upon performance, no goalkeepers indicated this to be the case. Following data collection, EyeVision software was used to capture the DVCR gaze recordings for further frame-by-frame analysis (QuickTime Player 7).

\section{Procedure and Design}

Data collection was carried out at the club's training venue for each goalkeeper. After a 10-min self-selected warmup, and calibration of the eye tracker, the participants performed four familiarization trials. Then, each goalkeeper faced 48 penalty kicks. Goalkeepers were instructed to try to save as many kicks as possible. Participants rested after every fourth kick, during which the calibration of the Mobile Eye was checked.

There were four experimental conditions: (a) 6-m nondeception, (b) 6-m deception, (c) 10-m nondeception, and (d) 10-m deception. Each condition consisted of 12 trials. Futsal laws dictate that penalties are taken from either $6 \mathrm{~m}$ (regular penalty) 
or $10 \mathrm{~m}$ (i.e., second penalty ${ }^{1}$ ). Although rules permit goalkeepers to step forward up to $5 \mathrm{~m}$ from the goal line during $10-\mathrm{m}$ kicks, in the current experiment, the goalkeepers were instructed to remain on the goal line. The kicking distance conditions were blocked and counterbalanced. For the deception strategy, the penalty takers were instructed to execute the kicks as though they were intending to kick and aim (i.e., look) to the opposite side of the goal that they would actually shoot (Dicks et al., 2010a). Penalty takers also reported to use other deception strategies (e.g., varying angle of hips; Lopes et al., 2014) during professional matches, so they were encouraged to use their usual deception routine. Deceptive and nondeceptive trials were randomly ordered within each distance block. Penalty takers were advised before each trial about the deception/ nondeception strategy and the side to aim toward, that is, they were to use a goalkeeper-independent strategy and were not allowed to adjust the side based on the goalkeepers' actions (Noël, van der Kamp, \& Memmert, 2015; van der Kamp, 2006). The number of the kicks directed toward both sides was balanced within conditions (i.e., $50 \%$ to right and 50\% to the left) and randomly ordered. No extra instructions were provided regarding the height of the kick and also not with respect to the length of the run-up. Kicks that deviated from the intended goal side or missed the goal were retaken at the end of the block.

\section{Data Analysis}

Kick descriptives. Ball flight time was computed from highspeed recordings, and was defined as the time between foot-ball contact and the moment the ball crossed the goal line (or interception). The location at which the ball entered the goalmouth (or was intercepted) was determined using Kinovea software (V.0.8.15), and defined as the vertical $(\mathrm{cm})$ and horizontal distance from the goal center $(\mathrm{cm})^{2}$

Performance measures. Performance of the goalkeepers was assessed offline from the high-speed video recordings (120 fps) using Kinovea software. Only three trials out of 576 were lost due to technical failure. Favorable to previous research (e.g., Dicks et al., 2010b), a second external researcher recoded 30 randomly selected trials, obtaining an interobserver reliability of $r=.93$ for trunk and $r=.83$ arm onset. Three performance measures were defined: (a) percentage of saves, (b) percentage of final dives to the same side as the ball, and (c) the percentage of movement corrections (i.e., the dive was initially made toward one side, and then, corrected with a final dive toward the opposite side). In addition, the timing of the dive was calculated using two measures: (a) trunk onset was defined as the first observable movement of the goalkeepers' trunk toward either side, and (b) arm onset was defined as the first observable movement of the hand actually directed toward the ball. The trunk and arm onset times were defined relative to the moment of foot-ball contact, with negative values denoting initiation before ball-contact.

Gaze measures. Goalkeepers' gaze patterns were analyzed frame by frame from the gaze recordings $\left(22.33 \mathrm{~Hz}^{3}\right)$. After dismissing five trials due to technical failure, $99.5 \%$ of the sample was analyzed. The reliability between coders relative to 30 randomly selected trials $(1,149$ frames recoded) was $r=.82$ for gaze data. The analysis of the gaze behavior comprised of the moment that the penalty taker's started the run-up $(M=-1,520 \mathrm{~ms}, S D=$
$18 \mathrm{~ms}$ ) up to initial part of ball flight (135 ms, after foot-ball contact; Dicks et al., 2010b). The run-up was divided into two temporal phases of the same duration. The first phase included the beginning of the run-up and penalty takers' first steps (i.e., from $-1,520$ to $-690 \mathrm{~ms}$ ), while the second phase included the last placement of the kicking leg on the ground, the last placement of the nonkicking leg, the kicking action, and initial portion of ball flight (i.e., from -690 to $135 \mathrm{~ms}$ ). Each frame of the gaze recordings was manually coded relative to 12 areas (see Figure 1): (a) the penalty taker's head, (b) the trunk region, (c) the hip region, (d) both feet, (e) space between ball and player (i.e., anticipated or future body location), (f) the kicking leg, (g) the nonkicking leg, (h) space between ball and nonkicking leg, (i) stationary ball, (j) space between ball and goalkeeper (anticipated or future ball location), (k) ball in flight, and (l) other (see Dicks et al., 2010b; Savelsbergh et al., 2002). Finally, to reduce the high dimensionality of gaze patterns, we calculated a ratio that represented the proportion of time spent gazing at the penalty taker's body relative to time spent gazing at the ball (Navia et al., 2013) ${ }^{4}$.

Statistics. After using Shaphiro-Wilk test $(95 \% \mathrm{CI})$ to verify that the data were normally distributed (Field, 2009), we submitted the kick descriptives and the performance measures to a series of separate 2 (Distance: $6 \mathrm{~m}, 10 \mathrm{~m}) \times 2$ (Strategy: deception, nondeception) analysis of variance with repeated measures on both factors (i.e., repeated-measures analysis of variance [RM-ANOVA]). For gaze measures, run-up phase (first phase, second phase) was added as an additional repeated measures factor. Mauchly's test was used to assess any violations for sphericity. Effect size of the RM-ANOVAs were expressed using partial eta-squared $\left(\eta_{p}^{2}\right)$, with values of $0.01,0.06$, and 0.14 representing small, medium, and large effects, respectively (Cohen, 1988). For dependent variables that were not normally distributed, Friedman ANOVA's were conducted, and main effects were assessed using Friedman multiple pairwise comparisons (least square difference) as a post hoc test. Effect sizes were expressed in $d$, with $0.2,0.5$, and 0.8 values of $d$ for small, medium and large effects respectively (Cohen, 1988).

\section{Results}

\section{Kick Descriptives}

Ball flight times were approximately $100 \mathrm{~ms}$ longer for $10-\mathrm{m}$ penalties compared to 6 -m penalties, $F(1,11)=339.33, p<.001$, $\eta_{\mathrm{p}}^{2}=.97$ (see Table 1). Furthermore, nondeception penalties had a

\footnotetext{
${ }^{1}$ Second penalties, which are similar to penalty kicks with the exception that they are taken from $10 \mathrm{~m}$ instead of $6 \mathrm{~m}$, are conceded every time that the opposing team commits six or more accumulated fouls during a half time (IFAB, 2016, pp. 44-46)

${ }^{2}$ As described, the camera was placed $0.5 \mathrm{~m}$ off-center from the penalty spot, resulting in a slightly trapezoid image of the goalmouth. Therefore, a custom-made algorithm was used to correct that optical distortion and calculate the actual values of ball height irrespective of ball side.

${ }^{3}$ This sample frequency was derived from a chronometric analysis of the gaze recording. For that purpose, goalkeeper recordings $(120 \mathrm{~Hz})$ and a supplementary chronometer were synchronized to determine the actual sample frequency of the gaze recordings.

${ }^{4}$ Head, trunk, hips, feet, kicking leg, nonkicking leg and space between ball and player (anticipated future body location) were grouped into body, whereas ball, ball in flight, space between ball and nonkicking leg (with more tendency toward the ball location) and space between ball and goalkeeper and were categorized as the ball.
} 

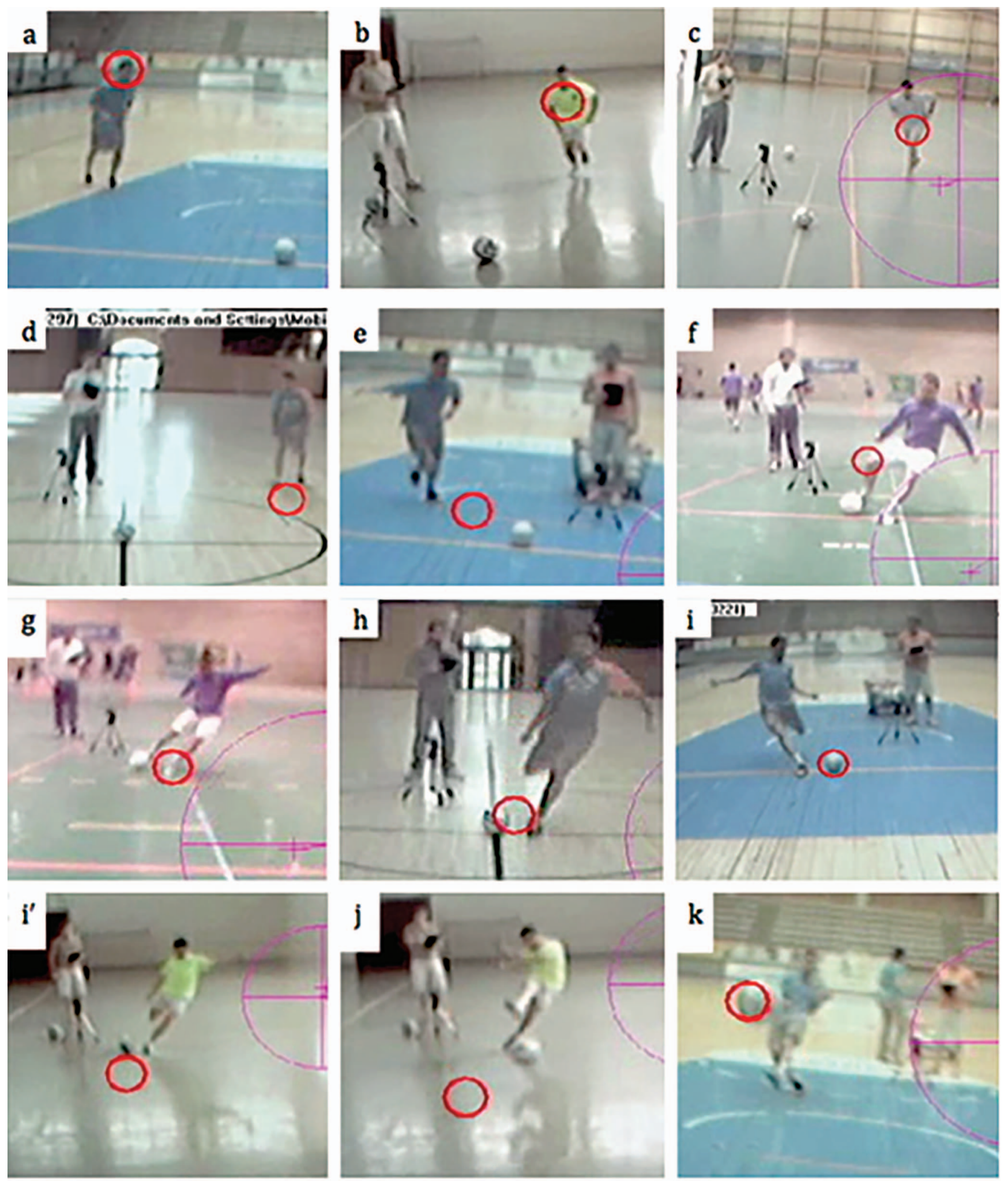

Figure 1. Areas of gaze location. Circle represents point of gaze. See the online article for the color version of this figure. 
Table 1

Means (and Standards Deviation) of Initiation Times (ms) and Ball Flight ( $\mathrm{ms}$ ) in the Four Conditions

\begin{tabular}{lrrrcr}
\hline & \multicolumn{2}{c}{$6 \mathrm{~m}$} & & \multicolumn{2}{c}{$10 \mathrm{~m}$} \\
\cline { 2 - 3 } \cline { 5 - 6 } \cline { 5 - 6 } Measures & Nondeception & Deception & & Nondeception & Deception \\
\hline Trunk onset & $-133(98)$ & $-133(72)$ & & $198(26)$ & $213(25)$ \\
Arm onset & $187(13)$ & $190(11)$ & & $211(13)$ & $213(14)$ \\
Ball flight & $284(19)$ & $293(21)$ & & $391(22)$ & $397(20)$ \\
\hline
\end{tabular}

shorter flight time than deception penalties, as revealed by a main effect of strategy $F(1,11)=5.32, p=.042, \eta_{\mathrm{p}}^{2}=.33$. On average, for the four conditions, the ball landed around $100 \mathrm{~cm}$ horizontal to the goal's center (see Figure 2). There were no main effects of distance or strategy on horizontal placement, but the two factors did significantly interact, $F(1,11)=6.07, p=.031, \eta_{\mathrm{p}}^{2}=.36$. Post hoc analysis indicated that during the 6-m penalties, the ball finished further from the vertical midline of the goal when the kickers used a nondeception strategy in comparison with deception strategy. Finally, penalty takers placed kicks significantly higher in the nondeception strategy condition compared to deception condition, $F(1,11)=6.62, p=.026, \eta_{p}^{2}=.37$. No further effects for vertical extent were found.

\section{Performance Measures}

Figure 3 depicts the participants' performance. Friedman test revealed that the percentage of saves significantly differed across conditions, $\chi^{2}(3)=26.40, p<.001$ (Figure 3a). Post hoc comparisons indicated that goalkeepers saved less $6-\mathrm{m}$ than $10-\mathrm{m}$ penalties (6-m nondeception vs. 10-m nondeception conditions, $T=-2.04, p=.001, d=2.33 ; 6$-m nondeception vs. $10-\mathrm{m}$ deception, $T=-1.92, p=.002, d=2.29 ; 6-\mathrm{m}$ deception vs. $10-\mathrm{m}$ nondeception, $T=-1.83, p=.003, d=2.29$; and 6-m deception vs. 10 -m deception, $T=-1.71, p=.007, d=2.25)$. There were no significant differences related to deception effect in the number of saves within both 6- and 10-m distances.

In line with the percentages of saves, the percentage of dives to the correct side of the goal differed across conditions, $\chi^{2}(3)=$ $30.39, p<.001$. Dives to the correct side occurred less frequently when facing 6-m penalties in comparison with $10-\mathrm{m}$ kicks $(6-\mathrm{m}$ nondeception vs. 10-m nondeception conditions, $T=-2.21, p<$ $.001, d=3.36$; 6-m nondeception vs. 10-m deception, $T=-1.96$,

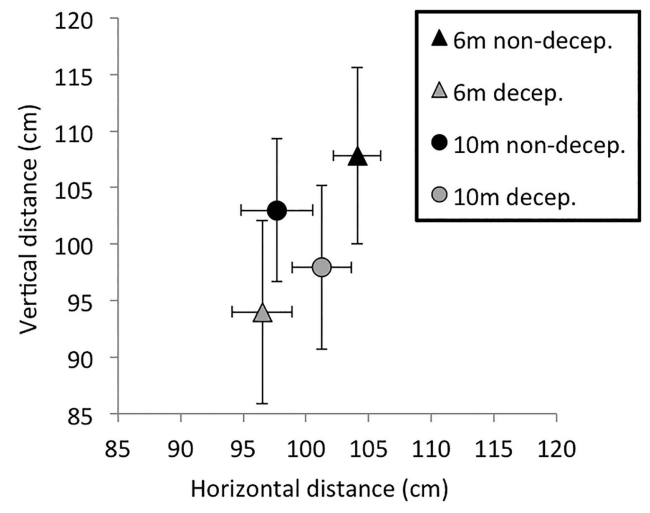

Figure 2. Location of the kicks in the four conditions. Error bars represent standard error.

$p=.001, d=3.16 ; 6-\mathrm{m}$ deception vs. 10-m nondeception, $T=$ $-2.04, p=.001, d=3.40$; and 6-m deception vs. 10-m deception, $T=-1.79, p=.004, d=3.20)$. No further differences were found.

Finally, the percentage of movement corrections also significantly differed across conditions, $\chi^{2}(3)=23.42, p<.001$ (Figure $3 c)$. Post hoc test revealed that goalkeepers corrected more frequently during 10-m deception condition trials than during both 6-m nondeception $(T=1.75, p=.005, d=2.10)$ and $6-\mathrm{m}$ deception kicks $(T=1.87, p=.002, d=2.25)$. Further post hoc effects were not found.

The goalkeepers adjusted the timing of their dive to the penalty distance but not to deception strategy (see Table 1), with the dive being initiated earlier during 6-m penalties (i.e., on average, before ball contact) in comparison with $10-\mathrm{m}$ penalties (i.e., on average, after ball contact). Accordingly, RM-ANOVAs confirmed significant effects of distance on trunk onset, $F(1,11)=211.02, p<$ $.001, \eta_{\mathrm{p}}^{2}=95$, and arm onset, $F(1,11)=29.85, p<.001, \eta_{\mathrm{p}}^{2}=$ 73. No further main or interaction effects were revealed.

\section{Gaze Measures}

In addition to distance (6 vs. $10 \mathrm{~m}$ ) and strategy (nondeception vs. deception) conditions, gaze variables were further divided into two temporal phases: the first phase encompassed the beginning of the penalty takers' run-up and first steps; and the second phase included the last steps before kicking, kicking action and first


Figure 3. Performance measures in the four conditions: (a) \% of balls saved, (b) $\%$ of correct side, and (c) $\%$ of corrections. ${ }^{* *} p<.01$. 

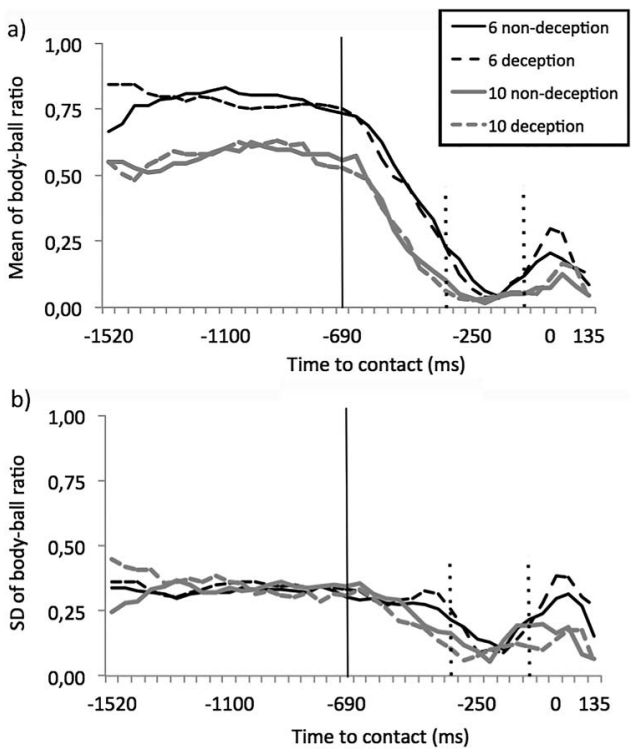

Figure 4. Evolution of the ratio representing viewing time spent looking at the body (i.e., 1.0) relative to viewing time to the ball $(0.0)$ in the four conditions: (a) mean, (b) standard deviation. Vertical dotted lines represent the average moment of penalty takers' last placement of kicking leg and last placement of nonkicking leg. The vertical solid line represents the division of the full length of the trials into two equal phases.

moments of ball flight (see Figure 4). To compare the current findings with previous work, we performed an initial descriptive analysis of the areas of gaze behaviors. As can be seen in Table 2, this revealed large variation between individual goalkeepers. Systematic differences of viewing time per areas across conditions were not found, with the exception that goalkeepers showed longer viewing time toward the penalty takers' head during the first phase of the trials compared to the second phase. Subsequently, gaze data locations were grouped intro either body or ball to enable the calculation of a body/ball gaze ratio variable (see method section).
Despite the interindividual variability in gaze patterns, three consistent features emerged. First, the majority of participants (10 out of 12) adopted a gaze pattern during which they first fixated the kicker's body and then the ball (Figure 4a). The RM-ANOVA revealed a significant effect of phase on body/ball gaze ratio, $F(1$, $11)=31.85, p<.001, \eta_{\mathrm{p}}^{2}=.74$, confirming a larger body/ball gaze ratio during the first phase of the run-up in comparison with the second phase (Figure 4a). That is, more time was spent looking at the penalty taker in the first phase of each trial, whereas more time was spent looking at the ball in the second phase.

Second, irrespective of condition, there was a higher variability in goalkeepers' body/ball gaze ratio for the first phase compared to the second phase, both between and within participants. The mean standard deviation of the first phase for the four conditions (interparticipants' variability) was larger than for the second phase, $t(3)=9.55, p=.002$ (Figure $4 b$ ). That is, in the first phase, there was a great deal of variation between goalkeepers in the utilized gaze patterns. Moreover, around $250 \mathrm{~ms}$ before contact, the mean value of body/ball gaze ratio was close to zero (Figure 4a) and the variability among participants was minimal (Figure 4b). In other words, interpretation of Figure 4 indicates that all the goalkeepers directed their gaze toward the ball and the gap between ball and nonkicking leg at the time between the kickers' last placement of the kicking leg and the placement of the nonkicking foot before foot-ball contact. Furthermore, goalkeepers showed a greater intraindividual variability between body and ball locations (variations of body/ball gaze ratio values across 12 trials) during the first phase of the run-up compared to the second phase, as RMANOVA confirmed a main effect of phase on standard deviation of body/ball gaze ratio, $F(1,11)=13.55, p=.004, \eta_{\mathrm{p}}^{2}=.55$. No further effects of distance, $F(1,11)=0.86, p=.373, \eta_{\mathrm{p}}^{2}=.07$, strategy, $F(1,11)=0.01, p=.932, \eta_{\mathrm{p}}^{2}=.01$, or interactions among factors were found for standard deviation of the body/ball gaze ratio.

Finally, as depicted in Figure 4a, during 6-m kicks goalkeepers looked more toward the body and less to the ball than during $10-\mathrm{m}$ kicks (in 10-m penalties they spent more time looking to the ball

Table 2

Percentage (and Standards Deviation) of Viewing Time per Areas During the Two Phases for the Four Conditions

\begin{tabular}{|c|c|c|c|c|c|c|c|c|}
\hline \multirow[b]{3}{*}{ Area } & \multicolumn{4}{|c|}{$6 \mathrm{~m}$} & \multicolumn{4}{|c|}{$10 \mathrm{~m}$} \\
\hline & \multicolumn{2}{|c|}{ Nondeception } & \multicolumn{2}{|c|}{ Deception } & \multicolumn{2}{|c|}{ Nondeception } & \multicolumn{2}{|c|}{ Deception } \\
\hline & First & Second & First & Second & First & Second & First & Second \\
\hline Head & $55(34)$ & $9(9)$ & $56(35)$ & $9(7)$ & $25(25)$ & $3(5)$ & $27(22)$ & $2(3)$ \\
\hline Trunk & $3(4)$ & $2(2)$ & $5(7)$ & $2(3)$ & $4(5)$ & $1(1)$ & $6(7)$ & $1(2)$ \\
\hline Hips & $4(8)$ & $2(3)$ & $4(9)$ & $1(2)$ & $6(13)$ & $2(3)$ & $5(11)$ & $2(3)$ \\
\hline Feet & $13(14)$ & $6(7)$ & $12(17)$ & $6(7)$ & $19(24)$ & $6(9)$ & $18(27)$ & $5(7)$ \\
\hline Soccer ball-player & $3(4)$ & $5(5)$ & $2(2)$ & $4(4)$ & $2(2)$ & $2(3)$ & $1(2)$ & $1(2)$ \\
\hline Kicking leg & $0(0)$ & $4(7)$ & $0(0)$ & $6(8)$ & $0(0)$ & $1(2)$ & $0(0)$ & $2(3)$ \\
\hline Nonkicking leg & $0(0)$ & $1(2)$ & $0(0)$ & $1(2)$ & $0(0)$ & $2(6)$ & $0(0)$ & $1(4)$ \\
\hline Soccer ball-nonkicking leg & $0(0)$ & $9(13)$ & $0(0)$ & $9(12)$ & $0(0)$ & $16(11)$ & $0(0)$ & $16(15)$ \\
\hline Ball & $22(31)$ & $55(23)$ & $21(32)$ & $55(21)$ & $43(30)$ & $59(20)$ & $42(32)$ & $60(20)$ \\
\hline Soccer ball-goalkeeper & $0(0)$ & $4(1)$ & $0(0)$ & $4(3)$ & $0(0)$ & $2(3)$ & $0(0)$ & $2(2)$ \\
\hline Ball flight & $0(0)$ & $2(2)$ & $0(0)$ & $3(3)$ & $0(0)$ & $6(2)$ & $0(0)$ & $5(2)$ \\
\hline Other & $0(1)$ & $1(1)$ & $0(0)$ & 1(1) & $0(0)$ & $1(1)$ & $0(1)$ & $1(1)$ \\
\hline Body & 78 & 28 & 79 & 28 & 57 & 16 & 57 & 16 \\
\hline Ball & 22 & 71 & 21 & 71 & 43 & 83 & 43 & 83 \\
\hline Ratio & .78 & .28 & .79 & .28 & .57 & .16 & .57 & .16 \\
\hline
\end{tabular}


after the onset of the run-up), as confirmed by the RM-ANOVA's main effect for distance $F(1,11)=9.83, p=.009, \eta_{\mathrm{p}}^{2}=.47$. Deception strategy condition did not show any effect on body/ball gaze ratio values, $F(1,11)=0.06 p=.805, \eta_{\mathrm{p}}^{2}=.006$, as well as no other significant interaction among factors was found.

\section{Discussion}

In the present study we examined gaze patterns, accuracy, and timing of expert futsal goalkeepers' movements while attempting to save deception and nondeception penalty kicks in situ. Crucially, this study aimed to reveal how an expert population controlled their gaze (and thus information pick-up) relative to changes in conflicting spatiotemporal demands of the interceptive task. Results revealed that performance and gaze patterns were highly influenced by changes in the spatiotemporal constraints of the task (distance condition), but not by the deceptive intention of the penalty takers (strategy condition). These main findings will now be considered at length in the remainder of the discussion.

\section{Performance}

Goalkeepers saved more kicks, started their saving action later, and spent more time fixating the ball during $10-\mathrm{m}$ penalties than during 6-m kicks. Previous research (e.g., Diaz et al., 2012) has revealed that early kinematic information from the penalty taker's actions prior to foot-ball contact is unlikely to support the accurate control of anticipation due to variability in the penalty takers' actions, which supports the use of deception (Lopes et al., 2014). In the present study, during 6-m kicks, goalkeepers appeared to prioritize arriving at the anticipated kick location with sufficient time to intercept the ball, and in doing so, exploited less reliable, nonspecifying kinematic variables (i.e., spent more time looking at the penalty taker) to anticipate kick direction. This perceptualmotor behavior resulted in comparatively less accurate anticipation of kick direction for 6-m kicks in comparison with $10 \mathrm{~m}$. During 10-m kicks, spatiotemporal constraints meant that goalkeepers moved later, meaning that they could exploit more reliable kinematic information arising from the final moments of the penalty taker's action (i.e., kicking action and first moments of ball flight) that supported both the accurate timing and direction of behavior (Triolet et al., 2013).

Temporal analysis of the goalkeepers' performance offers new insights into current understanding on interceptive actions relative to the model of affordance-based control (Fajen, 2005, 2007). Previous work has indicated that a performer's action capabilities place an action boundary of the timing of actions, whereby movements remain within a "safe" region to ensure that actions remain achievable (Fajen \& Devaney, 2006). In the current study, during 10-m kicks, goalkeepers potentially acted outside of a safe action boundary (see also Dicks et al., 2010c), showing an apparent inaccuracy in the scaling of actions (Fajen, 2005). On average, the ball flight time during 6-m kicks was $288 \mathrm{~ms}$ and goalkeepers started their saving action $133 \mathrm{~ms}$ before contact, which leaves a temporal margin of $421 \mathrm{~ms}$ for goalkeepers to complete their diving action and intercept the ball. During 10-m kicks, the average ball flight time was 394 ms, whereas goalkeepers started their saving action $205 \mathrm{~ms}$ after foot-ball contact, which meant that goalkeepers had a temporal margin of only $188 \mathrm{~ms}$. Bearing in mind that the space to cover (dimensions of the goalmouth) and the action capabilities (goalkeeper agility) did not vary across distance conditions, one may have expected to observe that goalkeepers would leave an equivalent amount of time for control of the interceptive action for both 6-m and 10-m kicks. However, results indicate that the control strategy of the goalkeepers changed between the two conditions (see also, Triolet et al., 2013). Following Faisal and Wolpert's (2009) 'optimal' stopping model, the shift in strategy can be understood as the goalkeepers placing increased emphasis on online or prospective control in the presence of more reliable information (10-m condition), while relying more upon a predictive control in the face of less reliable information (6-m condition; see also Panchuk \& Vickers, 2009). Hence, the temporal calibration of action capabilities across the changing spatiotemporal demands was not evenly scaled, but appeared to be dependent upon the trade-off between availability of reliable visual information and motor accuracy (Battaglia \& Schrater, 2007).

\section{Gaze Behavior}

The analysis of gaze control strategies revealed that, irrespective of distance and strategy conditions, participants differed in the gaze locations that they attended to during the first phase of the penalty takers' run-up. These individual differences in gaze patterns did not have any bearing on performance, which appears to reinforce the observation that attention to early information from the penalty taker's approach does not differentiate success in the control of saving actions (Diaz et al., 2012). These results therefore appear to be somewhat contradictory of the perspective adopted in previous anticipation gaze behavior studies, whereby it is purported that accurate visual control is predicated on the adoption of a consistent and repeatable "search strategy" that is replicated from one trial to the next (e.g., Abernethy, Schorer, Jackson, \& Hagemann, 2012; Savelsbergh et al., 2005). However, in both 6-m and $10-\mathrm{m}$ kicks, the variation in gaze patterns decreased during the later moments of the run-up. Participants, with no exception, looked at the ball (or gap between the ball and the nonkicking leg) during the final moments of the penalty takers' run-up (around 250 $\mathrm{ms}$ before contact). Note that this approximate time-frame before foot-ball contact corresponds with the availability of the most reliable sources of kinematic information for accurate anticipation of kick direction (Diaz et al., 2012; Lopes et al., 2014). This gaze finding therefore suggests that looking in the right time(s) at the right place(s) may, in fact, be most critical for successful performance during the control of interceptive actions (e.g., Mann, Spratford, \& Abernethy, 2013).

An important question relative to the findings highlighted above is whether gaze behaviors during real-time interceptive actions are an indication of information pick-up used to control the timing (when to move) or the direction (where to move) of actions. For example, it is possible that the highly consistent gaze orientation to the ball location (object to be intercepted) during the moments before foot-ball contact may reflect the pick-up of information for the temporal control of the saving action. Around $250 \mathrm{~ms}$ before contact, gaze may inform goalkeepers about the time to contact between the penalty taker and the ball, rather than information about the anticipated direction of the kick. Thereafter, information that unfolded around and following contact (kicking action and ball flight) may primarily support the spatial control of the inter- 
ceptive action. During 10-m penalties, goalkeepers tended to track the ball trajectory via a smooth pursuit gaze pattern. During 6-m kicks, in line with previous studies (Land \& McLeod, 2000; Mann et al., 2013; Ripoll \& Fleurance, 1988), goalkeepers situated their gaze toward the future predicted trajectory of the oncoming ball just at the moment of foot-ball contact; located either on the floor (in kicks when the goalkeeper dived in the wrong direction) or on the ball in flight (in kicks when the goalkeeper dived in the correct direction). This change in the orientation of attention (cf. Posner, 1980) or predictive gaze (Land \& McLeod, 2000), consisting of a saccadic movement toward a future location, would likely support the subsequent prospective control of the interceptive action, that is, the final spatial adjustments (i.e., arms to contact the ball) of the saving action (Montagne, 2005).

In sum, it is plausible that the gaze patterns utilized by expert goalkeepers in the current study provided optical information for both the temporal control of the saving action (i.e., time to contact) before contact, and spatial adjustments to the oncoming ball at the moment of foot-ball contact and after. These important findings call into question the primary role of gaze control during anticipation tasks, where there has been previous assumption that gaze is used to guide the spatial prediction of kick direction (e.g., Dicks et al., 2010b; Savelsbergh et al., 2002). To this end, a primary aim for studies of visual anticipation has tended to focus on the information that is exploited during judgment tasks, rather than the control of perception-action (van der Kamp et al., 2008). Given that previous work has revealed distinct differences in gaze control during judgment and reciprocal perception-action tasks (Dicks et al., 2010b), the present findings further suggest that anticipation skill is not only predicated on where to move but also when to move. During anticipation tasks, gaze appears to support the timing and direction of actions, both of which are highly interrelated.

Video-based judgment tasks remove the timing demand of anticipation as there is no interceptive action and therefore, a fundamental concern across extant studies is that the processes underpinning anticipation skill may have been misunderstood until now. In fact, the same concern has been raised for research in the wider field of social coordination, where worries for the fidelity of visual displays have obfuscated attention to time demands in natural environments (Schilbach et al., 2013). Hence, the current findings reflect gaze behaviors in the framework of emotional and perceptual engagement within a dynamic interaction between two individuals. Recently, Lappi (2016) highlighted some differences in gaze patterns between lab experiments and naturalistic tasks, calling for the consideration of new techniques when analyzing gaze behavior in complex real-world scenarios. The new layer of understanding on the control of interceptive actions offered by the present study is underpinned by the introduction of a new method for capturing the variability in gaze patterns across different temporal windows of the task. The funnel-like pattern (cf. Bootsma \& van Wieringen, 1990) that emerged around $250 \mathrm{~ms}$ prior to contact appears to reflect the pick-up of reliable information that emerges in the final phase of the opponent's action. Future work is needed to better understand how gaze control varies over time during a range of visual control tasks and such evidence is likely to have important implications for the future training of perceptual skill (for a recent review, see Dicks, van der Kamp, Withagen, \& Koedijker, 2015).

\section{Deception}

In contrast to previous findings in deception research (e.g., Sebanz \& Shiffrar, 2009), and more specifically in the soccer penalty kick (Dicks et al., 2010a; Smeeton \& Williams, 2012), goalkeepers in our study did not perform better during nondeception trials (see also Lopes et al., 2014). The null effect of deception was evident for both 6-m and 10-m penalty kicks, revealing that changes in spatiotemporal demands did not appear to directly contribute toward the effect that deception has on performance accuracy. However, given that goalkeepers moved later during 10-m kicks in comparison with $6 \mathrm{~m}$, one may subsequently expect some evidence of prospective control during the $10 \mathrm{~m}$ trials as a consequence of regulating spatial anticipation based on penalty taker kinematics (Dicks et al., 2010a). Results were indicative of such suggestion as goalkeepers corrected their initial saving action more frequently during 10-m deception with respect to both 6-m conditions. Moreover, given that ball speeds decreased during deceptive kicks in comparison with nondeception (Dicks et al., 2010c), it is apparent that the deception led to biomechanical alterations in the penalty takers kick kinematics. A question for future work is to further understand the changes in movement kinematics that correspond with variations in projectile velocities during anticipation (Lopes et al., 2014).

\section{Future Directions}

A further challenge for future work during interpersonal interactions is to better understand how gaze control is adapted to changes in the movement kinematics of the opposing person in a dyad, during the anticipation of deceptive and nondeceptive biological motions (for a video-based approach, see Alder, Ford, Causer, \& Williams, 2014). The use of deception implies that the reliability of different kinematic locations may change from one kick to the next due to movement variability. Thus, for one trial, one pattern of gaze may underpin success, and in the next instance, the exact same pattern of gaze will not lead to anticipation accuracy (Dicks, Button, Davids, Chow, \& van der Kamp, 2016). Moreover, it must be acknowledged that the measurement of gaze behaviors, as a method of perception-action research, is not without limitations, as the point of gaze may not necessarily reflect the location of information pick-up. Hence, future studies are likely to benefit from the combined use of gaze and biomechanical analyses to capture real-time interpersonal behavior (e.g., Lopes et al., 2014). Together, technological advances offer the potential to systematically measure participants' gaze and coordination patterns, to build a comprehensive picture of the processes underpinning the control of anticipation in spatiotemporal constrained tasks. Importantly, and in line with observations elsewhere (e.g., Laidlaw, Foulsham, Kuhn, \& Kingstone, 2011), a key implication for the of perception and action processes is the need to capture instances of interpersonal interactions in real-time under naturally occurring spatiotemporal demands.

In conclusion, with the more lenient spatiotemporal constraint (i.e., kick from $10 \mathrm{~m}$ ), the goalkeepers saved more kicks, initiated their actions later, and looked longer toward ball relative to the penalty takers' body. Furthermore, analysis of gaze patterns showed that variations in information pick-up were related to the unfolding of the penalty taker's action, revealing a funnel-like pattern toward the end of the action (Bootsma \& Van Wieringen, 
1990). To our knowledge, this study is the first to directly address how information pick-up during the scaling of actions is adapted to changes in conflicting environmental demands. The present study provides new understanding on the processes underpinning perception and action by suggesting more functions of information pick-up across time than previously reported. Moreover, the new method presented for examining temporal variations on the pick-up of optical variables offers a promising approach to further explore how gaze is controlled during interceptive actions.

\section{References}

Abernethy, B., Gill, D. P., Parks, S. L., \& Packer, S. T. (2001). Expertise and the perception of kinematic and situational probability information. Perception \& Psychophysics, 30, 233-252. http://dx.doi.org/10.1068/ p2872

Abernethy, B., Schorer, J., Jackson, R. C., \& Hagemann, N. (2012). Perceptual training methods compared: The relative efficacy of different approaches to enhancing sport-specific anticipation. Journal of Experimental Psychology: Applied, 18, 143-153. http://dx.doi.org/10.1037/ a0028452

Alder, D., Ford, P. R., Causer, J., \& Williams, A. M. (2014). The coupling between gaze behavior and opponent kinematics during anticipation of badminton shots. Human Movement Science, 37, 167-179. http://dx.doi .org/10.1016/j.humov.2014.07.002

Bartlett, F. C. (1932). Remembering. Cambridge, United Kingdom: Cambridge University Press.

Battaglia, P. W., \& Schrater, P. R. (2007). Humans trade off viewing time and movement duration to improve visuomotor accuracy in a fast reaching task. The Journal of Neuroscience, 27, 6984-6994. http://dx.doi.org/ 10.1523/JNEUROSCI.1309-07.2007

Bootsma, R., \& Van Wieringen, P. (1990). Timing an attacking forehand drive in table tennis. Journal of Experimental Psychology: Human Perception and Performance, 16, 21-29. http://dx.doi.org/10.1037/ 0096-1523.16.1.21

Brenner, E., Driesen, B., \& Smeets, J. B. (2014). Precise timing when hitting falling balls. Frontiers in Human Neuroscience, 8, 342. http://dx .doi.org/10.3389/fnhum.2014.00342

Cohen, J. (1988). Statistical power analysis for the behavioural sciences (2nd ed.). New York, NY: Academic Press.

Diaz, G. J., Fajen, B. R., \& Phillips, F. (2012). Anticipation from biological motion: The goalkeeper problem. Journal of Experimental Psychology: Human Perception and Performance, 38, 848-864. http://dx.doi.org/10 $.1037 / \mathrm{a} 0026962$

Dicks, M., Button, C., \& Davids, K. (2010a). Availability of advance visual information constrains association-football goalkeeping performance during penalty kicks. Perception, 39, 1111-1124. http://dx.doi.org/10 $.1068 / \mathrm{p} 6442$

Dicks, M., Button, C., \& Davids, K. (2010b). Examination of gaze behaviors under in situ and video simulation task constraints reveals differences in information pickup for perception and action. Attention, Perception \& Psychophysics, 72, 706-720. http://dx.doi.org/10.3758/APP .72.3.706

Dicks, M., Button, C., Davids, K., Chow, J. Y., \& van der Kamp, J. (2016). Keeping an eye on noisy movements: On different approaches to perceptual-motor skill research and training. Sports Medicine. Advance online publication. http://dx.doi.org/10.1007/s40279-016-0600-3

Dicks, M., Davids, K., \& Button, C. (2010c). Individual differences in the visual control of intercepting a penalty kick in association football. Human Movement Science, 29, 401-411. http://dx.doi.org/10.1016/j .humov.2010.02.008

Dicks, M., Van der Kamp, J., Withagen, R., \& Koedijker, J. (2015). Can we hasten expertise by video simulations?" Considerations from an ecological psychology perspective. International Journal of Sport Psychology, 46, 587-607.

Faisal, A. A., \& Wolpert, D. M. (2009). Near optimal combination of sensory and motor uncertainty in time during a naturalistic perceptionaction task. Journal of Neurophysiology, 101, 1901-1912. http://dx.doi .org/10.1152/jn. 90974.2008

Fajen, B. R. (2005). Calibration, information, and control strategies for braking to avoid a collision. Journal of Experimental Psychology: Human Perception and Performance, 31, 480-501. http://dx.doi.org/10 $.1037 / 0096-1523.31 .3 .480$

Fajen, B. (2007). Affordance-based control of visually guided action. Ecological Psychology, 19, 383-410. http://dx.doi.org/10.1080/ 10407410701557877

Fajen, B. R., \& Devaney, M. C. (2006). Learning to control collisions: The role of perceptual attunement and action boundaries. Journal of Experimental Psychology: Human Perception and Performance, 32, 300-313. http://dx.doi.org/10.1037/0096-1523.32.2.300

Field, A. (2009). Discovering statistics using SPSS (3rd ed.). London, United Kingdom: Sage.

Huys, R., Smeeton, N. J., Hodges, N. J., Beek, P. J., \& Williams, A. M. (2008). On the dynamic information underlying visual anticipation skill. Perception \& Psychophysics, 70, 1217-1234. http://dx.doi.org/10.3758/ PP.70.7.1217

International Football Association Board (IFAB). (2016). Futsal laws of the game. Zurich, Switzerland: FIFA.

Laidlaw, K. E., Foulsham, T., Kuhn, G., \& Kingstone, A. (2011). Potential social interactions are important to social attention. Proceedings of the National Academy of Sciences of the United States of America, 108, 5548-5553. http://dx.doi.org/10.1073/pnas.1017022108

Land, M. F., \& McLeod, P. (2000). From eye movements to actions: How batsmen hit the ball. Nature Neuroscience, 3, 1340-1345. http://dx.doi .org/10.1038/81887

Lappi, O. (2016). Eye movements in the wild: Oculomotor control, gaze behavior \& frames of reference. Neuroscience and Biobehavioral Reviews, 69, 49-68. http://dx.doi.org/10.1016/j.neubiorev.2016.06.006

Lees, A., \& Owens, L. (2011). Early visual cues associated with a directional place kick in soccer. Sports Biomechanics, 10, 125-134. http://dx .doi.org/10.1080/14763141.2011.569565

Lopes, J. E., Jacobs, D. M., Travieso, D., \& Araújo, D. (2014). Predicting the lateral direction of deceptive and non-deceptive penalty kicks in football from the kinematics of the kicker. Human Movement Science, 36, 199-216. http://dx.doi.org/10.1016/j.humov.2014.04.004

Mann, D. L., Spratford, W., \& Abernethy, B. (2013). The head tracks and gaze predicts: How the world's best batters hit a ball. PLoS One, 8, e58289. http://dx.doi.org/10.1371/journal.pone.0058289

Mann, D. T., Williams, A. M., Ward, P., \& Janelle, C. M. (2007). Perceptual-cognitive expertise in sport: A meta-analysis. Journal of Sport \& Exercise Psychology, 29, 457-478. http://dx.doi.org/10.1123/ jsep.29.4.457

Montagne, G. (2005). Prospective control in sport. International Journal of Sport Psychology, 36, 127-150.

Morya, E., Bigatăo, H., Lees, A., \& Ranvaud, R. (2005). Evolving penalty kick strategies: World Cup and club matches 2000-2002. In T. Reilly, J. Cabri, \& D. Araújo (Eds.), Science and Football V (pp. 237-242). London, United Kingdom: Taylor \& Francis.

Navia, J. A., van der Kamp, J., \& Ruiz, L. M. (2013). On the use of situational and body information in goalkeeper actions during a soccer penalty kick. International Journal of Sport Psychology, 44, 234-251. http://dx.doi.org/10.7352/IJSP2013.43.000

Noël, B., van der Kamp, J., \& Memmert, D. (2015). Implicit goalkeeper influences on goal side selection in representative penalty kicking tasks. PLoS One, 10, e0135423. http://dx.doi.org/10.1371/journal.pone .0135423 
Núñez, F. J., Oña, A., Bilbao, A., \& Raya, A. (2005). Anticipation in soccer goalkeepers during penalty kicking. International Journal of Sport Psychology, 36, 284-298.

Panchuk, D., \& Vickers, J. N. (2006). Gaze behaviors of goaltenders under spatial-temporal constraints. Human Movement Science, 25, 733-752. http://dx.doi.org/10.1016/j.humov.2006.07.001

Panchuk, D., \& Vickers, J. N. (2009). Using spatial occlusion to explore the control strategies used in rapid interceptive actions: Predictive or prospective control? Journal of Sports Sciences, 27, 1249-1260. http:// dx.doi.org/10.1080/02640410903156449

Piras, A., \& Vickers, J. N. (2011). The effect of fixation transitions on quiet eye duration and performance in the soccer penalty kick: Instep versus inside kicks. Cognitive Processing, 12, 245-255. http://dx.doi.org/10 .1007/s10339-011-0406-z

Posner, M. I. (1980). Orienting of attention. The Quarterly Journal of Experimental Psychology, 32, 3-25. http://dx.doi.org/10.1080/ 00335558008248231

Ripoll, H., \& Fleurance, P. (1988). What does keeping one's eye on the ball mean? Ergonomics, 31, 1647-1654. http://dx.doi.org/10.1080/0014 0138808966814

Savelsbergh, G. J., Van der Kamp, J., Williams, A. M., \& Ward, P. (2005). Anticipation and visual search behaviour in expert soccer goalkeepers. Ergonomics, 48, 1686-1697. http://dx.doi.org/10.1080/00140130 500101346

Savelsbergh, G. J., Williams, A. M., Van der Kamp, J., \& Ward, P. (2002). Visual search, anticipation and expertise in soccer goalkeepers. Journal of Sports Sciences, 20, 279-287. http://dx.doi.org/10.1080/ 026404102317284826

Schilbach, L., Timmermans, B., Reddy, V., Costall, A., Bente, G., Schlicht, T., \& Vogeley, K. (2013). Toward a second-person neuroscience. Behavioral and Brain Sciences, 36, 393-414. http://dx.doi.org/10.1017/ S0140525X12000660

Sebanz, N., \& Shiffrar, M. (2009). Detecting deception in a bluffing body: The role of expertise. Psychonomic Bulletin \& Review, 16, 170-175. http://dx.doi.org/10.3758/PBR.16.1.170
Smeeton, N. J., \& Williams, A. M. (2012). The role of movement exaggeration in the anticipation of deceptive soccer penalty kicks. British Journal of Psychology, 103, 539-555. http://dx.doi.org/10.1111/j.20448295.2011.02092.x

Triolet, C., Benguigui, N., Le Runigo, C., \& Williams, A. M. (2013). Quantifying the nature of anticipation in professional tennis. Journal of Sports Sciences, 31, 820-830. http://dx.doi.org/10.1080/02640414.2012 .759658

van der Kamp, J. (2006). A field simulation study of the effectiveness of penalty kick strategies in soccer: Late alterations of kick direction increase errors and reduce accuracy. Journal of Sports Sciences, 24, 467-477. http://dx.doi.org/10.1080/02640410500190841

van der Kamp, J., \& Renshaw, I. (2015). Information-movement coupling as a hallmark of sport expertise. In J. Baker \& D. Farrow (Eds.), Routledge Handbook of Sport Expertise (pp. 50-63). London, United Kingdom: Routledge.

van der Kamp, J., Rivas, F., Van Doorn, H., \& Savelsbergh, G. (2008). Ventral and dorsal system contributions to visual anticipation in fast ball sports. International Journal of Sport Psychology, 39, 100-130.

Vilar, L., Araújo, D., Davids, K., Correia, V., \& Esteves, P. T. (2013). Spatial-temporal constraints on decision-making during shooting performance in the team sport of futsal. Journal of Sports Sciences, 31, $840-846$

Walsh, V. (2014). Is sport the brain's biggest challenge? Current Biology, 24, R859-R860. http://dx.doi.org/10.1016/j.cub.2014.08.003

Yarrow, K., Brown, P., \& Krakauer, J. W. (2009). Inside the brain of an elite athlete: The neural processes that support high achievement in sports. Nature Reviews Neuroscience, 10, 585-596. http://dx.doi.org/10 $.1038 / \mathrm{nrn} 2672$

Received March 17, 2016

Revision received October 20, 2016

Accepted October 24, 2016 